\title{
Effect of Be on Aging Behavior of an Al11Si3Cu Cast Alloy
}

\author{
Guiqing Wang ${ }^{a}$, Long Wang ${ }^{\mathrm{b}}$
}

Department of Material Science and Technology, Shandong Jianzhu University, Fengming Road, Lingang Development District, Jinan 250101, China

awangguiqing@126.com, bcasting82@126.com

Keywords: aluminum cast alloy; age hardening; precipitation; effect of Be.

Abstract. Effect of Be addition on age hardening and precipitation behaviors of Al11Si3Cu alloy was investigated by hardness measurement and differential scanning calorimetry (DSC) analysis. The age hardening results show that $0.25 \% \mathrm{Be}$ addition increases the peak hardness of $\mathrm{Al} 11 \mathrm{Si} 3 \mathrm{Cu}$ alloy about $20 \mathrm{HV}$. DSC results show that Be addition inhibits precipitation of $\mathrm{Cu}$ and /Si clusters or GP zones before artificial aging and increases the volume of $\theta^{\prime}$ precipitates during artificial aging. The precipitation dynamic analysis results show that $\theta^{\prime}$ phases are two-dimensional precipitates that is unaffected by $\mathrm{Be}$ addition. The nucleation density dependent parameter $k$ for Be containing alloy is 2.75 times of the base alloy, which suggests that Be addition accelerates the nucleation density of $\theta^{\prime}$ phases.

\section{Introduction}

Artificial age treatment for T4 treatment sample is an important method to improve the mechanical properties of Al-Si-Cu cast alloys, which is called the T6 treatment ${ }^{[1,2]}$. The T4 treatment consists of solution treatment at a high temperature to dissolve the intermetallic compounds and homogenize the alloying elements in $\alpha(\mathrm{Al})$ followed by quenching at a high cooling rate to retain a high concentration of vacancies and solutes in $\alpha(\mathrm{Al})$. For $\mathrm{Cu}$ contain aluminum alloys, $\mathrm{Cu}$ atoms oversaturated in $\alpha(\mathrm{Al})$ after $\mathrm{T} 4$ treatment and coherent $\theta^{\prime \prime}$ and/or $\theta^{\prime}$ phases precipitated with the duration of artificial aging treatment to produce the maximum strengthening of the material ${ }^{[3-5]}$. Heat treatment parameters, such as solution temperature and time, quenching temperature, artificial aging temperature and time, could have a great influence on age hardening behaviors ${ }^{[6,7]}$.

In addition, alloying elements have important influence on age hardening behavior of aluminum alloys ${ }^{[8-10]}$. Early study shows that Be addition to aluminum alloy increases the age hardening response $^{[11,12]}$. In this research, the effect of Be on the age hardening and precipitation behaviors of $\mathrm{Al11}$ Si3Cu cast alloy has been studied by hardness measurement and DSC analysis.

\section{Results and discussion}

Effect of Be on age hardening precipitation. Fig. 1 shows age hardening behaviors at $180{ }^{\circ} \mathrm{C}$ for heating T4 samples of $\mathrm{Al} 11 \mathrm{Si} 3 \mathrm{Cu}$ and $\mathrm{Al11} \mathrm{Si} 3 \mathrm{Cu} 0.25 \mathrm{Be}$ alloys respectively. Hardness increases after aging more than $240 \mathrm{~min}$ and attains $110 \mathrm{HV}$ at about $900 \mathrm{~min}$ for Al1 $1 \mathrm{Si3Cu}$ alloy, but there is a slight hardness decrease at the early stage of aging for this alloy. Hardness increases with aging time and attains $130 \mathrm{HV}$ at about min For $\mathrm{Al} 11 \mathrm{Si} 3 \mathrm{Cu} 0.25 \mathrm{Be}$ alloy. The age hardening results show that $\mathrm{Be}$ addition increases the age hardening response of $\mathrm{Al} 11 \mathrm{Si} 3 \mathrm{Cu}$ alloy. Because there is little age hardening effect for Al-Be binary alloy ${ }^{[11]}$, the effect of Be additions on age hardening of $\mathrm{Al} 11 \mathrm{Si} 3 \mathrm{Cu}$ may be attributed to the precipitation mechanisms.

The phenomena of the nucleation and growth of precipitation phases were investigated by DSC. Fig. 2 shows the DSC curves of T4 treated Al11 Si3Cu and $\mathrm{Al} 11 \mathrm{Si} 3 \mathrm{Cu} 0.25 \mathrm{Be}$ samples at a heating rate of $10{ }^{\circ} \mathrm{C} \mathrm{min}^{-1}$. There is an endothermic peak between $100-200{ }^{\circ} \mathrm{C}$ and an exothermic peak is detected between $200 \sim 350{ }^{\circ} \mathrm{C}$ for $\mathrm{Al} 11 \mathrm{Si} 3 \mathrm{Cu}$ alloy. Based on age precipitation analysis of Al-Si-Cu cast alloys, exothermic peak at around $250{ }^{\circ} \mathrm{C}$ may be caused by $\theta^{\prime}$ precipitation that are the main age hardening precipitates for $\mathrm{Al} 11 \mathrm{Si} 3 \mathrm{Cu}$ alloy ${ }^{[2,5]}$. Endothermic peak between $100-200{ }^{\circ} \mathrm{C}$ may be 
caused by the dissolution of clusters or GP zones precipitated before aging, which leads to the hardness decrease at early aging stage of $\mathrm{Al1} 1 \mathrm{Si} 3 \mathrm{Cu}$ alloy as shown in Fig.1. Exothermic peak at around $150{ }^{\circ} \mathrm{C}$ corresponding with GP zones precipitation and exothermic peak at around $250{ }^{\circ} \mathrm{C}$ caused by $\theta^{\prime}$ precipitation are detected for Al1 $1 \mathrm{Si} 3 \mathrm{Cu} 0.25 \mathrm{Be}$ alloy. Comparing two DSC curves in Fig.2, Be addition inhibits precipitation of $\mathrm{Cu}$ and / $\mathrm{Si}$ clusters or GP zones before artificial aging.

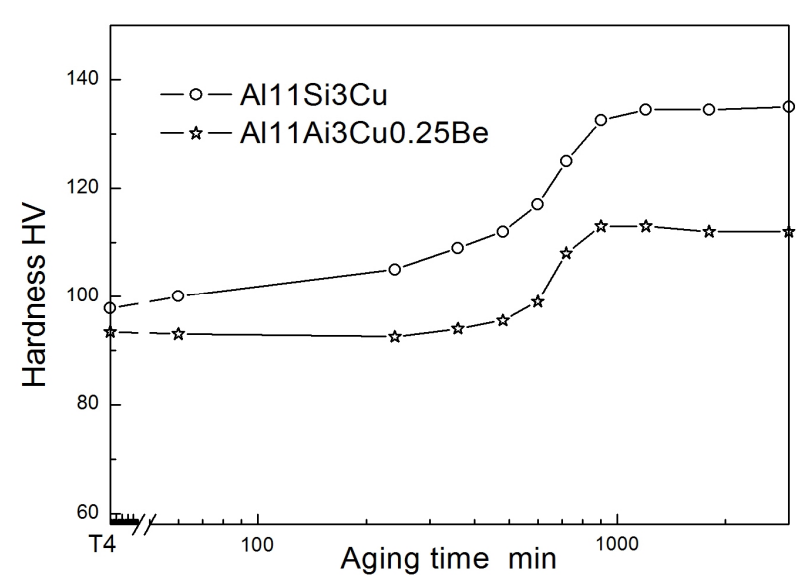

Fig.1: Hardness vs. $\lg t$ for $\mathrm{T} 4$ samples aged at $180{ }^{\circ} \mathrm{C}$

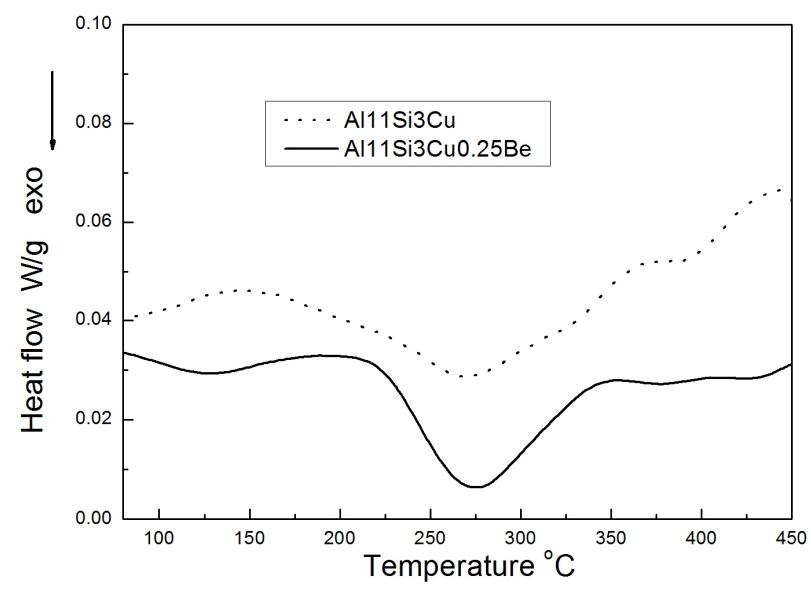

Fig.2: DSC curves at a heating rate of $10{ }^{\circ} \mathrm{Cmin}^{-1}$

Heating the $\mathrm{T} 4$ treatment samples to $180{ }^{\circ} \mathrm{C}$ with a heating rate of $10 \mathrm{~K} \mathrm{~min}^{-1}$ and holding at this temperature, the isothermal DSC curves both of $\mathrm{Al11} \mathrm{Si} 3 \mathrm{Cu}$ and $\mathrm{Al11} \mathrm{Si} 3 \mathrm{Cu} 0.25 \mathrm{Be}$ are shown in Fig.3. Exothermic peaks detected in isothermal DSC curves should correspond with precipitation of $\theta^{\prime}$ phases. There is an incubation period before precipitation reaction for both alloys. The precipitation process of $\theta^{\prime}$ phases starts at $50 \mathrm{~min}$ and ends at $800 \mathrm{~min}$ for $\mathrm{Al} 11 \mathrm{Si} \mathrm{Cu}$ alloy. For $\mathrm{A} 11 \mathrm{Si} 3 \mathrm{Cu} 0.25 \mathrm{Be}$ alloy, the precipitation process of $\theta^{\prime}$ phases starts at $150 \mathrm{~min}$ and ends at $850 \mathrm{~min}$. This result suggests that $\mathrm{Be}$ addition to $\mathrm{Al}-11 \mathrm{Si}-3 \mathrm{Cu}$ alloy promotes $\theta^{\prime}$ precipitation.

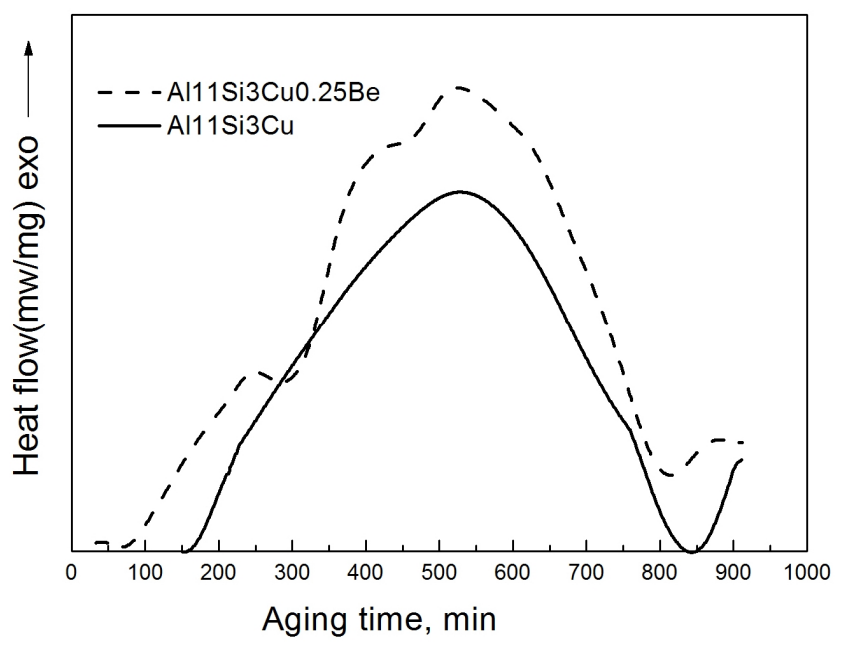

Fig.3 Isothermal DSC curves at $180{ }^{\circ} \mathrm{C}$

The amount of heat released from the precipitation reaction during aging should be proportional to the volume of the precipitates. The heats released during $\theta^{\prime}$ precipitation are $38 \mathrm{kJmol}^{-1}$ and $43 \mathrm{kJmol}^{-1}$ respectively for $\mathrm{A} 111 \mathrm{Si} 3 \mathrm{Cu}$ and $\mathrm{A} 111 \mathrm{Si} 3 \mathrm{Cu} 0.25 \mathrm{Be}$ alloys respectively. This indicates that adding $0.25 \%$ wt $\mathrm{Be}$ addition to $\mathrm{Al}-11 \mathrm{Si}-3 \mathrm{Cu}$ alloy has increased the volume of $\theta^{\prime}$ during aging , which is consistent with the age hardening response shown in Fig. 1. 
Precipitation kinetic analysis. The volume fraction of $\theta^{\prime}$ increases along with artificial aging time and reaches a maximum amount after a long period aging time that peak hardness has been attained.

According to DSC analysis by Malinov and Guo ${ }^{[15]}$, the transformed fraction of the precipitate is equal to the fraction of heat released.

$$
f(t)=\frac{\int_{t_{S}}^{t} \frac{\partial h}{\partial t} d t}{\int_{t_{S}}^{t_{E}} \frac{\partial h}{\partial t} d t}=\frac{\int_{t_{S}}^{t} H d t}{\int_{t_{S}}^{t_{E}} H d t}
$$

Where $t_{S}$ and $t_{E}$ represent the start and end time of transformation respectively, $f(t)$ represents transformed fraction at time $t, H$ is the measured heat flow.

From the DSC signal of Fig. 3 and equation (1), the fraction of $\theta^{\prime}$ precipitates $f(t)$ as a function of the aging time $t$ can be calculated and plotted. The calculated results for $\mathrm{Al1} 1 \mathrm{Si} \mathrm{Cu}$ and Al1 $1 \mathrm{Si} 3 \mathrm{Cu} 0.25 \mathrm{Be}$ alloys aging at $180^{\circ} \mathrm{C}$ are plotted as shown in Fig.4.

The kinetics of isothermal transformations is usually expressed by the Avrami type equation:

$$
f(t)=1-\exp \left(-k t^{n}\right)
$$

Where $n$ is a parameter depending on the growth mechanism of precipitates, and $k$ is a nuclei density parameter.

Fig. 5 shows the liner relationship of $\lg \ln (1 /(1-f))$ versus $\lg t$ that is calculated according data shown in Fig.4, and $n$ and $k$ can be calculated from the slope and the ordinate intercept. The parameters $n$ are 2.4 and 2.6 for $\mathrm{Al} 11 \mathrm{Si} 3 \mathrm{Cu}$ and $\mathrm{Al} 11 \mathrm{Si} 3 \mathrm{Cu} 0.25 \mathrm{Be}$ alloys respectively, which is consistent with the observed piece like morphology of $\theta^{\prime}$ precipitates (two-dimensional growth), and also indicates that the growth mechanism of the $\theta^{\prime}$ precipitate is unaffected clearly by the Be addition. The calculation results show that the nucleation density dependent parameter $k$ for $\mathrm{Be}$ containing alloy is 2.75 times of the base alloy, which indicates that the Be addition accelerated the nucleation density for $\theta^{\prime}$ precipitate.

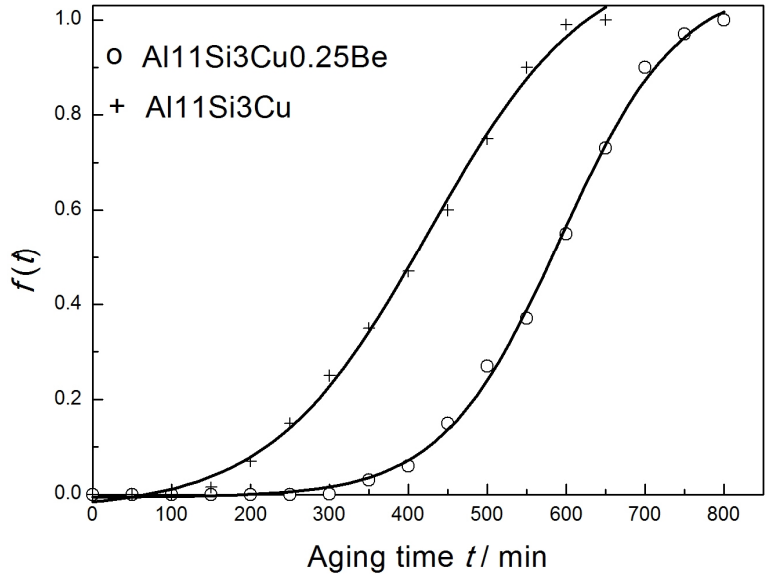

Fig.4 Transformed volume fraction vs. aging time

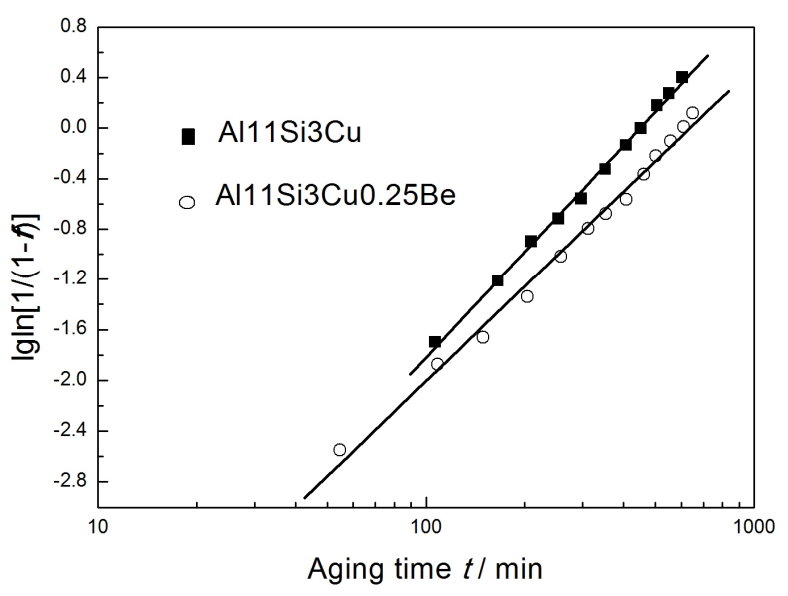

Fig.5 $\lg \ln (1 /(1-f))$ versus $\lg t$ for samples aged at $180^{\circ} \mathrm{C}$

\section{Discussions}

The microstructure of the $\mathrm{T} 4$ treatment sample of $\mathrm{Al} 11 \mathrm{Si} 3 \mathrm{Cu}$ cast alloy is in non-equilibrium that vacancies, $\mathrm{Cu}$ and $\mathrm{Si}$ atoms are oversaturated in $\alpha(\mathrm{Al})$. The oversaturated vacancies will accumulate during $\mathrm{T} 4$ samples stored at room temperature that accelerate the diffusing of $\mathrm{Si}$ and $\mathrm{Cu}$ atoms to 
form $\mathrm{Si}$ and/or $\mathrm{Cu}$ atoms clusters. Heating this $\mathrm{T} 4$ sample to $180^{\circ} \mathrm{C}$ for artificial aging, the $\mathrm{Si}$ and/or $\mathrm{Cu}$ atoms clusters formed at room temperature will dissolve because the size of Si and/or Cu clusters is not big enough as the nuclei of $\theta^{\prime}$ phases. This phenomenon is verified by the DSC curve shown in Fig. 2 that an endothermic peak between $100-200{ }^{\circ} \mathrm{C}$ is detected for $\mathrm{Al} 11 \mathrm{Si} 3 \mathrm{Cu}$ cast alloy. The hardness decrease at early aging stage of $\mathrm{Al1} 1 \mathrm{Si3} \mathrm{Cu}$ alloy as shown in Fig.1 should be caused by the dissolution of $\mathrm{Si}$ and/or $\mathrm{Cu}$ atoms clusters formed at room temperature before artificial aging. Moreover, there are little homogenous nuclei acted as the nuclei of $\theta^{\prime}$ phases that should lead to $\theta^{\prime}$ phases precipitating at grain boundaries.

The addition of $0.25 \% \mathrm{Be}$ to $\mathrm{Al} 1 \mathrm{Si} 3 \mathrm{Cu}$ cast alloy increasing the nucleation density of $\theta^{\prime}$ phases can be explained by the high Be-vacancy binding energy $\left(0.26 \mathrm{eV}^{[12]}\right)$ in Be containing alloy. For the T4 sample of Al11 Si3Cu0.25Be alloy, oversaturated vacancies will combined with Be atoms because of the high Be-vacancy binding energy that inhibits the diffusion of $\mathrm{Si}$ and $\mathrm{Cu}$ atoms to form $\mathrm{Si}$ and/or $\mathrm{Cu}$ atoms clusters during stored at room temperature. Heating this $\mathrm{T} 4$ sample to $180^{\circ} \mathrm{C}$ for artificial aging, the vacancies initially bound by $\mathrm{Be}$ are released and accelerate the diffusing of $\mathrm{Si}$ and $\mathrm{Cu}$ atoms to form $\mathrm{GP}$ zones at around $150{ }^{\circ} \mathrm{C}$ that is verified by the endothermic peak between $100-200{ }^{\circ} \mathrm{C}$ in DSC curve of Al11 Si3Cu0.25Be cast alloy shown in Fig.2. These GP zones should act as the nuclei of $\theta^{\prime}$ phases that accelerated the precipitation $\theta^{\prime}$ phases and then higher age hardening response has been obtained.

\section{Conclusions}

Addition $0.25 \% \mathrm{Be}$ to $\mathrm{Al} 11 \mathrm{Si} 3 \mathrm{Cu}$ alloy increase age hardening response obviously and peak hardness $130 \mathrm{HV}$ is obtained for samples aging at $180^{\circ} \mathrm{C}$ about $900 \mathrm{~min}$.

The precipitation mechanism of $\theta^{\prime}$ phases is unaffected clearly by the Be addition, but Be addition accelerated the nucleation density of $\theta^{\prime}$ precipitates.

\section{Acknowledgements}

This work was financially supported by the Shandong Natural Science Foundation (ZR2012EMM014).

\section{References}

[1]H.G.Kang, M.Kida, H.Miyahara, K.Ogi, AFS Transctions,27(1999)507-515.

[2]Janusz Krol, Materials \& Design, 18(1997)345-347.

[3]Amporn Wiengmoon, John.T.H.Pearce, Torranin Chairuangsri, Seiji Isoda, Hikaru Saito and Hiroki Hurata, Micron, 45(2013)32-36.

[4]L.Bourgeois, C.Dwyer, M.Weyland, J.F.Nie and B.C. Muddle, Acta Materialia, 59(2011)7043-7050.

[5]D.Ovono Ovono, I.Guilot and D.Massinon, Scripta Materialia, 55(2006)259-262.

[6]S.Haro, J.Ramirez, D.K.Dwivedi, E.Martinez, Materials Science and Technology, 25(2009)886-891.

[7]Saleh Alkahtani, Materials and Design, 41(2012)358-369.

[8]P Ouellet, F H Samuel, Journal Of Materials Science, 34(1999)4671-4697.

[9]J.Y.Hwang, R.Banerjee, H.W.Doty and M.J. Kaufman, Acta Materialia, 57(2009)1308-1317.

[10]L.Bourgeois, C.Dwyer, M.Weyland, J.F.Nie and B.C. Muddle, Acta Materialia, 60(2012)633-644.

[11]G.Q.Wang, X.F.Bian and J.Y.Zhang, Acta metallurgica sinica, 1(2003)43-46(in Chinese).

[12]W. V. Youdellis and W.Fang, Materials Science and Technology, 10(1994)1031-1041.

[13]S.Malinov and Z.Guo, Metallurgical and Materials Transactions A, 32A(2001)879-887. 